\title{
Wii Are Family: Performing Race in Neo-liberal Europe $^{1}$
}

\author{
KATRIN SIEG
}

This article examines the flash mob dance Glow by the Afro-Norwegian duo Madcon, which was performed at the Eurovision Song Contest in Oslo, Norway, in 2010. The dance was modelled on the format of popular Wii dance games, and coordinated black and white dancers, families, mass publics and prerecorded and live footage in order to choreograph European 'unity in diversity'. The use of black dancers as avatars urging dancing crowds towards greater kinaesthetic sensitivity raises the questions of how race is figured in neo-liberal visions of cosmopolitan Europe, and what role gaming technology plays in facilitating cross-racial empathy and ethical responsiveness at a time when solidarity is fraying as a consequence of fiscal crises and austerity measures. Finally, the article considers Afro-European academic, activist and artistic practices as alternatives to neo-liberal regimes of race.

A great deal of the scholarship on global communications media welcomes and romanticizes the stretching of racial, ethnic and national intimacies across continents and along migration patterns, connecting diasporas with distant origins and constituting community through satellite signals and fibre-optic lines. The instantaneous accessibility and wide delivery of images and information on the Web can arouse sympathy and compassion for distant others, aid fundraising for victims of tsunamis and earthquakes, and fuel enthusiasm for faraway revolutions. In his book The Empathic Civilization, sociologist Jeremy Rifkin celebrates the advent of the 'age of empathy' warranted by mirror neurons in our brains, and facilitated by the global information networks that birthed a planetary consciousness. ${ }^{2}$ Carolyn Calloway-Thomas, author of Empathy in the Global World, likewise regards digital media as the midwife of intercultural literacy and global responsiveness to distant others brought close to us via Web, mobile phones and social-networking technologies. ${ }^{3}$ At the same time, others have noted, webcast images of violence and suffering have exacerbated phobic and violent responses, and hardened perceptions of essential alterity. The recording and circulation of videos documenting the beheading of Wall Street Journal journalist Daniel Pearl, the hanging of American mercenaries in Fallujah and the torture of inmates in Iraq's Abu Ghraib prison catalysed rigorous critical engagements with the question of empathy in this new environment of distant loves and proximate enemies. Norwegian mass murderer Anders Behring Breivik, who killed seventy-seven people in Oslo in July 2011, felt buoyed by a (perhaps imaginary) transnational network of 'Knights Templar' on the Web, and prepared for 
his killing spree by playing World of Warcraft and other, first-person shooter, games for sixteen hours a day over a whole year. Electronic media, then, which are undoubtedly redefining sociality, are evidently capable of both fostering and impeding empathy with others who might reside close by but are nevertheless perceived as alien. Rather than trust in global media to cultivate our innate empathic capacities, I take my cue from dance scholar Susan Leigh Foster, who, in her book Choreographing Empathy, studies choreographies for the ways in which they have both blocked and cultivated empathy during the age of colonialism and after. ${ }^{4}$ While digital technologies seriously strain the sustained attention to present others on which empathy hinges, Foster argues, digital technologies can also assist in practising kinaesthetic responses, which might blossom into ethical responsiveness and responsibility for others.

Film, art and theatre historians have noted that theories of empathy arose in conjunction with emergent technologies of immersion, from the Wagnerian Gesamtkunstwerk to early cinema. ${ }^{5}$ Whereas for art historian Robert Vischer, who coined the term Einfühlung in 1872, empathy denotes the observer's individual response to the artwork, philosopher Edith Stein later noted the collective dimension of empathy, as crowds experience a shared 'we' in response to the artwork. ${ }^{6}$ For Stein, this collective empathic sensation does not meld individuals into an undifferentiated mass, but enhances the feeling of difference and connectedness. ${ }^{7}$ The field of crowd psychology, which also arose in the late nineteenth century, however, reveals considerable ambivalence about the crowd as noble embodiment of mass sovereignty on the one hand, and as the threatening spectre of mobs manipulated by political demagogues and the new mass cultural technologies on the other. The constellation in which empathy is currently explored - defined by even more immersive global communications and entertainment technologies, by the neurological basis of empathy, and by increasingly heterogeneous compositions of crowds - similarly vacillates between asserting the digital media's capacity to ideologically interpellate users, and also enabling them to respond sensitively and critically to others. I would like to examine one performance here that seeks to forge what I would consider normative empathic pathways across historically vested differences in Europe. Dissecting the so-called normative can show us precisely how these differences are currently being refashioned, and discover in its choreography the deep codes that govern evolving, racialized concepts of European selfhood. The 'flash mob dance' Glow by the Afro-Norwegian duo Madcon was performed at the 2010 Eurovision Song Contest (ESC) in Oslo, Norway. The song did not run as part of the contest, or represent a particular nation, but endeavoured to illustrate that year's motto to 'share the dream' of European unity and diversity. The choreography of the dance folded diverse individuals, families and mass publics into a community of Europeans; through practising concerted physical movement and seeing that movement mirrored and extended by multiplying crowds on-screen, the flash mob dance sought to conjoin European motion and emotion.

The European Union (EU) has made great strides towards increased economic and political integration in the past two decades. Connections between member nations into a European polity have both intensified through an ever more elaborate web of institutions and expanded through several rounds of northern and eastern enlargement. 
Defining itself as a post-industrial knowledge economy, the creative industries, including the entertainment sector, are playing a central role in carving out a competitive place for the EU internationally. Yet the administrative consolidation of Europe as a supranational polity and single market has not been accompanied to the same degree or in the same top-down fashion by a cultural policy aimed at building a shared European identity. ${ }^{8}$ Nonetheless, a multitude of stakeholders are making claims to European identity and community. While Germany and France have long invested in ideas of European culture and civilization and tend to speak of European identity as an empirical reality rather than a fiercely contested process, non-EU member states such as Norway, as well as non-EU organizations such as the European Broadcasting Union (EBU), affirm the existence of 'European culture' as part of a language of belonging, recognition and partnership.

The ESC is a unique annual event where European identity and community are staged in three-minute performances of songs presented by participating nations. It is one of the longest-running and most popular television shows in the world, with more than 125 million spectators watching the broadcast on television and computer screens in recent years, many of whom participate in the voting process. In the past two decades the show has grown into an increasingly glitzy event that stretches over three days in May, supplemented by lively Internet forums commenting on the national selection processes during the months preceding the live broadcast. Hosting nations spare no expense or technical wizardry to showcase their creative prowess and advertise their attractions to visitors and viewers. Over the past decade and a half, romantic and familial metaphors have been used to emphasize reciprocal desire and organic cohesion among western and eastern Europeans, but the origin of these metaphors in colonial fantasies, which historically cemented racialized hierarchies between Nordic and Slavic peoples, for instance, also raised the spectre of permanent inequality and dependence between 'old' and 'new' Europeans. ${ }^{9}$ More recently, we can witness the revision of the family metaphor, now risen from the ashes of patriarchy, imperialism and state racism, and rejuvenated as a cosmopolitan consociation intent on mutual cooperation rather than authoritarian coercion. Kinship metaphors have stretched to include queer relatives, as well as members from different races and ethnicities. The contest has become a central venue for staging neo-liberal regimes of race, where not only do performers of colour warrant their respective nations' pluralism and tolerance, but also racial difference begins to animate and energize the European self. ${ }^{10}$

Norway's burgeoning oil industry and declining birthrate have necessitated a steady flow of guest workers and immigrants since the 1970s. While the largest influx comes from EU countries like Sweden and Poland, there are also sizeable groups of Pakistani, Iraqi and Somali immigrants and their descendants. First- and second-generation immigrants make up about thirteen percent of the Norwegian population, according to government statistics of 2012. ${ }^{11}$ This puts Norway below other European countries (in Germany, for instance, nineteen percent of the population has a 'migration background'), but the steep increase in recent years, and traditional self-perception of Nordic countries as ethnically homogeneous, have had Norwegian public media struggling to catch up with the demographic trend and stay responsive to an increasingly heterogeneous audience. Public broadcasters have adopted 'best practices' disseminated by the EBU, 
which developed a handbook (Diversity Toolkit) and has held workshops on diversity for broadcast journalists and officials. ${ }^{12}$ The Norwegian broadcasters of the 2010 ESC modelled a cosmopolitan Europe on the levels of performers, hosts and audience, right out of the EBU's Diversity Toolkit. The selection of the three hosts, Haddy Jatou N'jie, Erik Solbakken and Nadia Hasnaoui, attempted to visually emphasize the new demographic realities. ${ }^{13}$

Glowinvited the eighteen thousand spectators at the live event in Oslo, the thousands of people at public viewing sites across Europe and millions of television viewers to synchronize their bodies with the virtual community of Europeans through a sequence of rehearsed dance moves. As an attendee at the finale in Telenor Arena, I-along with the other eighteen thousand paying spectators - practised these moves under the supervision of an energetic dance instructor prior to the beginning of the broadcast. Fans could learn these moves ahead of time by taking a YouTube tutorial. ${ }^{14}$ At the appointed time, we watched the Madcon duo enter at the back of the arena and move through the central aisle towards the giant screens at the front. The screens began to pipe in prerecorded footage from public sites across Europe, followed by dozens of living rooms full of dancing celebrants from far-flung corners of the continent, until the cameras in the arena, now pointing at the audience, finally went live and we received the command to move in concert. A 'flash mob dance' merges the idea of the flash flood with the news flash: it rapidly assembles people in public spaces by means of social-networking technologies, and simulates a spontaneous eruption of movement that transforms unruly mobs into a synchronized mass. While the ordering, integrative effect of the flash mob dance bears a certain resemblance to fascist choreography, such as Mary Wigman's large-scale choreography at the 1936 Olympics in Berlin, the Eurovision flash mob dance differs from its fascist predecessors in at least three important respects: European bodies are depicted as both uniform and diverse; European space is constituted through outdoor shots of mass publics and domestic glimpses of families; and European identity is kinaesthetically enacted through the imbrication of live performance and virtual images. ${ }^{15}$

Glow is divided into three parts: it begins with a long tracking shot in medium close up that shows the Madcon duo move speedily through the aisles of Telenor Arena, their path cleared by security guards in dark suits. ${ }^{16}$ In this long first shot, the two men advance towards the camera through an undulating mass of white spectators, many wrapped in national colours and waving flags. Madcon seem to continually emerge from the sea of nationalized bodies that momentarily retreats from the centre to the border of the frame, until they arrive at the stage and the crowd becomes the backdrop to their performance. The camera then pulls back and swoops up, to capture the spread of the flash mob dance throughout the entire arena in an extreme long shot from above. The chaotic clashing of national accessories morphs into a grid of coloured dots, offering an image of orderly, coordinated movement. Blackness, as a star attribute, is part of this choreography of differentiation and ordering: initially part of a chaotic multinationality, it finally occupies a space outside the rhythmicized pixels that denote the crowd's body on-screen.

In the second sequence, the screen begins to pipe in footage from public streets, squares and bridges in Spain, Iceland, Slovenia, Sweden, Lithuania, the UK, Germany 
and Ireland, before returning to the inside of the arena. Sites not only are selected to include every point of the compass and every region of Europe, but also represent big and small countries, as well as old and new Eurovision participants. Crowds in this sequence are not only overwhelmingly young (between ten and twenty years old) and white, they also display a preponderance of pink and white clothes, which reflects the ESC's effort to coordinate the flash mob images with the 2010 logo of the Eurovision brand. ${ }^{17}$ Homogeneous in age and appearance, the flash mobs signify European diversity first and foremost in national terms flagged by the locations noted on the screen. Although prerecorded, this sequence simulates a spontaneous and simultaneous extension of movement, as the flash mob is shown to roll across the continent. As it builds, it transforms the initial exuberant running and hopping we observe in Spain and Iceland into extended and increasingly demanding phrases of the flash mob choreography by the time we reach Gothenburg and Vilnius. These more challenging scenes had been practised and performed by dance students whose schools had signed up with the ESC. The sequence as a whole dramatizes the harnessing of physical energy and movement: the amateur's clumsy joy of movement, which always risks poking one's neighbour in the eye or stepping on her feet, is channelled into more disciplined executions that require and foster - a high degree of kinaesthetic awareness. The Dublin scene shows rather virtuosic teenagers dancing in the street as well as in a gallery overlooking the scene, and thereby makes explicit the evolution of mass culture into expert and artistic craftsmanship choreographed in Glow. The shot from Gothenburg includes a Afro-Swedish girl placed one step in front of the flash mob; her graceful moves and precise phrasing justify her position as lead dancer, yet, as in the first sequence, the conflation of blackness with performative expertise strains against the rhetoric of racial inclusiveness - she embodies the apex of kinaesthetic proficiency but is also thereby set apart from the crowd.

In the third part, the screen cycles through festively decorated, flag-festooned living rooms with Eurovision viewers from all thirty-nine participating countries. It shows families watching television, eating, clapping and attempting to copy the flash mob dance moves with great hilarity and varied success, including a shot of the Norwegian crown princess Mette-Marit with her children. Shot in medium close up, the sequence emphasizes heterogeneity and cheerful unruliness: a plethora of ethnic and national signifiers is multiplied with a multigenerational age range, and conjugated across classes from rural to royal. The camera lingers on shots of the most expert dancers yet, piped in from an outdoor stage in Hamburg, before it resumes its tour of European living rooms, and then travels across the North Sea back to Telenor Arena. The Hamburg broadcast, with its public setting and professional dancers, breaks the thematic focus on family and domesticity of this sequence. The Afro-German dancers at the centre of the screen might epitomize the agility, precision and control demanded by the most advanced portion of the flash mob dance, but they cannot be accommodated by the familial rhetoric of multinational Europe. The ethnic diversity of families is occasionally underscored by folkloristic costumes and décor, yet they remain internally homogeneous. In the third segment, then, the integrative logic of neo-liberal cosmopolitanism, which promises to resolve the exclusionary logic of the nation, fractures to reveal that racial difference remains in an indeterminate, external relation to Europe. The sequence offers 
the third iteration of developing excited yet undirected movement into recognizable dance phrases, yet the rhetoric of racial inclusiveness and dancerly expertise bifurcates: on the one hand, the familial troping of Europe exposes its whiteness; on the other, the unmooring of expert movement from kinaesthetic community separates work from play. The manic energy infusing the repetitive, mechanistic movements of the Afro-German dancer, who punches each motion and clenches his muscles, making his exertions look more like labour performed under duress, is in high contrast to the partying families bookending his performance. Despite the moonwalk-like glide incorporated in the phrase he dances, he cannot quite manage to make industry look as effortless as Michael Jackson did. ${ }^{18}$

The graceful, ballerina silhouette of the girl in front of the crowd in Gothenburg from the first sequence visualizes the gorgeous diversity of Europe, and epitomizes the beauty and gratification of moving in sync. Her position allegorizes the integrative logic of cosmopolitan Europe that promises to fold all into the inclusive embrace of transnational community enriched by differences. This promise is made explicit by the lyrics, which articulate the EU motto 'unity and diversity' with the Eurovision slogan of 2010: 'Let us share this moment / Let's enjoy this night / Get the world connected / Though you are one of a kind.' 19 The first two parts of the flash mob dance synchronize 'diverse' bodies in a fantasy of spontaneous, self-generated governmentality, in which structural inequalities, racialized exclusions and social hierarchies are all smoothed over. Black bodies are energized by their historical association with music, dance and sports, and are positioned front and centre as the motor of a European economy driven by creative industry. The joyous, seemingly spontaneous dance embodies the European dream of docile, relentlessly active bodies working for fun. Offering black artists as ego ideals of the European creative economy, this choreography of meritocratic inclusion, of course, also appeals to those for whom recognition as European is easier to come by in symbolic form than it has been in political, social or economic terms.

As the paradoxical status of race as internal and external to the European family demonstrates, Glow's use of this organic metaphor, however, cannot shed the social distinctions and racialized hierarchies this metaphor trails in its nationalist and imperialist histories. ${ }^{20}$ The lyrics veer into a minoritizing, self-exoticizing language when the singers reference (themselves? as) 'lords of the underground, part of the jungle'. Together with their sexually suggestive moves, Glow's lyrics conflate global hip hop's bad-boy urban underdog imagery with much older stereotypes linking black men with primitivism and fetid African jungles in clearly fetishizing ways. The song's lyrics, just like its choreography, seek to include race and also assign it a special place within Europe. They avow an essentialist, even pathologized, assertion of racial difference, in order to revalue it as a mark of distinction, an excess of vigour and talent.

The history of racial spectacle that the Madcon duo's appearance, antics and music bring into play, however, notably neither is specifically Norwegian nor references a broadly European story of racial entertainment and labour. Instead, Yosef Wolde-Mariam and Tshawe Baqwa, whose parents came from Ethiopia and Eritrea and from South Africa respectively, evoke a racial imaginary in which conquest, colonialism and neo-colonial commerce are eclipsed by the history of cultural contact with African-Americans. Their 
iridescent sharkskin suits hark back to a long history of African-American entertainers in Europe, from the musicians and minstrels touring the nineteenth-century cabarets to the well-known performances of African-American jazz artists in Paris and Weimarera Berlin, to the great suffusion of American popular music in post-war European culture. ${ }^{21}$ The performers' cornrows update this tradition with a more contemporary, hip hop style, for which they are otherwise known in Norway and beyond. The curious fact that two Norwegians of African descent reference African-American musical idioms in a choreographic conjuring of European identity bespeaks the detachment of the terms race and racism from official discourses of post-war, post-Holocaust European identity. $^{22}$ As Europeans, by expunging all references to race, reimagined themselves as 'post-racial' societies, constructions of difference and discrimination in the context of decolonization and mass labour migrations, for instance, could not be analysed as racialized formations. Moreover, the racial strife that played out in the American occupying forces around desegregation and civil rights reinforced their perception that racism was a uniquely American problem. Black performers could - more than any other ethnic group - function as privileged, positive embodiments of European 'diversity' and tolerance. The critique of American racism displaced a more self-critical confrontation with homegrown, European racism.

Positioned as global ciphers of black vigour stripped of national or regional history, Madcon animate the spectacle of a European transracial economy whose success hinges fundamentally on the rerouting and reorientation of kinaesthesia through and towards digital technology. Madcon's performance simulates that process by modelling itself after gaming platforms like the Wii (2006) and Kinect (2010), which organize the full-body kinaesthetic interface of users with virtual space through motion-capture technology. Computer gaming, long associated with adolescent male loners engaging in violent misogynistic and racist role play, managed not only to rebrand itself as family entertainment and thus capture exponentially larger market shares, but to commend Wii gaming as the very matrix of sociability. ${ }^{23}$ Wii dance parties have already shaped the social relations and intersubjectivity of high-school students in North America, Europe and Australasia over the course of the last decade. The point of the games is to reroute kinaesthesia - the perception of 'joint positioning, muscular exertion and orientation within space' that creates awareness of the body's positioning in relation to the earth's gravity, other human bodies and the environment - through computers, to a much greater degree than the mouse interface, or GPS location technology. ${ }^{24}$ Wii and Kinect animate the deliberate and intense reworking of kinaesthesia not only through expanded options for customizable avatars, but through the participatory rhetoric of the Web 2.0, according to which race is understood and encouraged as a user-generated choice. ${ }^{25}$ The relationship of ESC fans in the arena, and of viewers watching the broadcast in their living rooms or at outdoor public viewing sites, with Madcon was clearly patterned on the Wii and Kinect grammar. The duo croon and clown in the space between crowd and screen. Their digitally manipulated voices, which vacillate between human and machine, signal a cyborg positionality. The refrain 'Glow, Glow' features a faintly perceptible switch from human $\mathrm{G}$ to the electronically processed 'low'; the digital yodel emulates the joyous jacking of the body into the electronic surround. The holographic swirl and fake 
three-dimensionality of their suit fabric recall the neon-coloured halo surrounding Wii avatars, called Miis. As Miis, Madcon-are-us: their giddy, uncoordinated movements lack the precision and vigour of the black flash mob dancers, but are more in line with the exuberant white crowds. Madcon are far from any performative virtuosity, notwithstanding the swirling leg lift, hip thrust and crotch grab that cite the late King of Pop's signature moves. However, they constitute a more fun, sexually unleashed version of us, which promises to guide us to the kinaesthetic proficiency displayed by the Hamburg dancers. The increasing expertise and agility of the black avatars paraded in Glow not only simulates avatars' evolving competence as dancers, but also facilitates viewers' illusion of increasing mastery over the avatar as Spielfigur (game figure) standing in for them. Feminist philosopher Astrid Deuber-Mankowsky has argued that this sense of mastery, which in the Wii and Kinect formats involves the viewer's entire body, is the basis of the ever-tighter loop of desire and identification between user and avatar, which ties them to the game and heightens its pleasure. At the same time, she points out, the Spielfigur does not really work for us; as Werbefigur (logo), the avatar works for the brand it advertises. ${ }^{26}$ Nor do avatars of racial difference really work for the populations to which they appear to refer; rather, they catalyse enthusiasm for capitalism as the harbinger of a borderless world, whose utopian promise is the eradication of obsolete nationalist, racist and sexist barriers to economic flows. This version of the neo-liberal European subject is energized by cultural differences, now reconfigured as desirable resources to be mined. This emphatically diverse capitalism tends to be embodied by hip, virile, racialized men emblematized by the Madcon duo, who both reference a distinct Other and function as ego ideals for the European self.

It is not at all far-fetched to regard Europe as a brand, or to understand Madcon's Glow as a musical logo for this brand. Not only is the EU itself making extensive use of globally visible brand consultants, it has also encouraged new and prospective EU member states particularly to rely on branding techniques for image management and loyalty building. ${ }^{27}$ Several of the east European ESC winners in the last decade were groomed by the Ukrainian firm CFC, which specializes in nation branding. The ESC, which itself achieved a coherent brand image only in 2004, now strives for synergy with national, regional and corporate brands. Although the instruments of EU branding have much in common with the historic tools of nation building enumerated by Benedict Anderson, from flags and coins to anthems and monuments, nations were able to bind citizens through expanded participation in government, lively public spheres and vigorous civil societies. ${ }^{28}$ By contrast, the EU's need to marshal empathy for brand loyalty arguably arose out of its notorious democratic deficit. As the disconnect between citizens and transnational governance deepened with each round of enlargement, political decision making became the province of non-elected technical experts. ${ }^{29}$ While rehearsals for Glow were under way, the common European market and polity were already deeply shaken, and structural inequalities between central and peripheral economies came to the fore. As the rifts deepen between those affected by harsh austerity programmes and those dictating and benefiting from them, white Europeans' hostilities against immigrants and minorities of colour are exacerbated. In this context, Glow's emulation of the Wii, the most advanced form of electronically mediated sociability, stages Europeans' faith in 
technologies that not only promise prosperity for all, but also simulate cross-cultural empathy and communal loyalty. Reading the European Wii through a media-critical lens, however, reveals that this dance - like the European enterprise it allegorizes merely orients our bodies, senses and feelings towards a technocratic apparatus whose mechanisms, perspectives and interests remain utterly opaque. It positions black Europeans as engines of the creative economy, but elides ever more urgent questions about race as a social formation governing social exclusions, exploitative divisions of labour and resource distribution. Glow perfectly choreographs European democracy.

Many ESC acts, which feature black performers, obscure more fraught axes of racialized difference prevailing in their respective contexts: the performance of AfroCaribbean singer Dave Benton, who helped Estonia win in 2001, eclipsed deep tensions surrounding the Russian minority in the Baltic country. In the same year that Madcon cheered for Europe, black singers also featured in the contributions representing Albania, where both ethnic Serbs and Roma are extremely vulnerable minorities; France, whose large post-colonial population is notoriously restive; and Switzerland, which affronted Muslim residents with its minaret ban the year before.$^{30}$ In each of these instances, the presence of black performers deflected from racialized populations, forms of oppression and struggles that cannot simply be pegged to skin colour. Racialization affects the status of Russian minorities in the Baltic states, of Roma in central European countries and in the Balkans, of indigenous people such as the Sami in the Nordic countries, and of Muslims who immigrated either from former colonies or as part of large-scale guestworker programmes since the 1960s. While the situation of indigenous or immigrant minorities that remain largely invisible at the ESC is often made more precarious by their lack of citizenship, the high cultural visibility that Afro-European entertainers enjoy compared to other minorities does not ensure stronger political representation, nor does citizenship status eliminate other (cultural, economic or social) forms of racialization, as the situation of Afro-German citizens demonstrates. The hypervisibility of AfroEuropeans and the centrality of blackness to European discourses of diversity do not open up towards a representation of locally specific ethnic differences, or a reckoning with European histories and practices of racialization, past and present. In particular, the relationship between contemporary conditions of globalized migration and commerce on the one hand, and the colonial past on the other, which is severed in Madcon's Glow, needs to be examined.

Afro-European activist organizations and academic networks have undertaken this work since the 1980s. Many anthologies and monographs that first mapped postcolonial and critical race studies in the European context sought to dispel ideologies of national exceptionalism; uncover continuities and changes in post-war practices and policies of racialization; compare and contrast the racializing regimes that attended colonialism, orientalism, fascism and globalization; and historicize and theorize race out from under the dominant Anglo-American paradigm. In the last decade, international and interdisciplinary research consortiums such as Black European Studies, which hosted two conferences in 2005 and 2006, and the Nordic Colonial Mind, which held three workshops in 2009 and 2010, have tried to integrate national specificity in more comparative approaches to European critical race studies. A growing number of blogs 
now link users across the continent, and inform them about Afro-European history, news and networking opportunities. ${ }^{31}$ The multi-author volumes After the Nazi Racial State: Difference and Democracy in Europe, Complying with Colonialism: Gender, Race, and Ethnicity in the Nordic Region, and Black Europe and the African Diaspora (all 2009), and the massive anthology A Historical Companion to Postcolonial Literature: Continental Europe and Its Empires (2011) each constitute groundbreaking efforts to gather, systematize and compare colonial and post-colonial histories. ${ }^{32}$ The latter includes peripheral European countries like Denmark, Italy and Portugal, whose erstwhile colonial enterprises have received much less scholarly attention than the better-researched British, French, Spanish, Belgian, Dutch and German empires. Scholars in the Nordic countries have begun to examine their region's own direct or indirect relationship with colonialism and the Eurocentric world view, and pierce the exceptionalist fiction that, because they 'have no colonial past', they therefore do not suffer from the 'colonial hangover of cultural oppression, economic exploitation, and political repression'. ${ }^{33}$

In addition, artists working in fine arts and popular culture have sought to create wider awareness about historical and contemporary formations of race in a range of venues and media. The work of Afro-Danish artist Jeannette Ehlers, which has been exhibited in Danish art galleries and internationally, for instance, offers sophisticated reflections on Denmark's implication in colonialism and slavery. ${ }^{34}$ Ehlers's densely poetic series of photographs and videos titled ATLANTIC include the video Black Magic at the White House (2009), which is set in the mansion of Marienborg, once owned by a prominent Danish slave trader and sugar merchant, and now the residence of Denmark's prime minister. A soundtrack of African drums conjures and enlivens the past in the shape of a black woman, who draws on the parquet and then dances through the presidential mansion. At first, we only see her shadow, and occasionally her reflection in a mirror, but as the piece progresses we catch glimpses of the dancer-in-the-flesh, as if the dance were magically, albeit fleetingly, restoring her bodily presence. She is both a historic spectre and our contemporary, laying claim to the expropriated products of her labour and reclaiming her place. Ehlers's technique consists of painstakingly erasing parts of the digital images and then patching the deleted parts by hand to conform to the background. The effect is a spectral outline of the deleted portion, as if the air were shimmering in the shape of the person that used to be there. In Black Magic, Ehlers puts the historic presence of slaves at Marienborg, and in the Danish colonial empire at large, under erasure, and thereby makes visible what has been officially abolished (an overtly racialized economy) yet continues to shape Denmark's current affluence. Black Magic does not present a simple narrative of restored visibility, electronically facilitated presence, or national and transracial communion, but leaves spectators with an absence, albeit one that pulses with unrealized life at the symbolic centre of the nation. The piece foregrounds the digital construction of images, and rouses the observer to empathy not least through its lively soundtrack, yet it blocks facile identifications across the charged lines of race.

The Afro-Norwegian performance group Queendom (founded in 1999), an allwomen company, tour widely with shows that combine political satire and popular music, and have also produced a book and sketches for television. Their satires, which 
aired on television in 2009, tackle the vicissitudes of fashioning Afro-Norwegian identity in a context defined by the widening gap between dominant perceptions of Norwegian cosmopolitan tolerance and minorities' painful experience of religious bigotry, racist violence and nativist traditions. ${ }^{35}$ One episode parodies the televisual gaze at Africa, which reproduces images of feminized poverty in order to legitimate European economic and political interventions, by first inviting the viewers' look and then breaking its alignment with the camera. Queendom's performances mark the apex of classical identity politics, embedded in a coalition of feminist and anti-racist movements. After the July 2011 massacre perpetrated by Anders Breivik, the group participated in a concert mourning the victims, and facilitating grief and healing. One of Queendom's members is Haddy Jatou N'jie, a black Norwegian and one of the three hosts at the Oslo Contest. N'jie's appearance at the ESC probably recalled for many Norwegians her satirical commentary on racial matters, but could not forestall her fetishization as a glamorous icon of racial difference for the majority of distant viewers. The simultaneous presence of Haddy Jatou N'jie and Madcon on the Eurovision stage references two different paradigms of racial politics, but subordinates anti-racist identity politics to the corporate marketing of ethnicity and race as an aspect of cosmopolitan nation and region branding.

The video installations and television episodes by Ehlers and Queendom demonstrate that digital technologies can assist in practising kinaesthetic responses that provide alternatives to the kinds of self and social relations into which capitalist screens are hailing us. These artists intensify and thereby make conscious the multiple ways in which our bodies are hailed and reoriented by digital technologies that not only have become normative and unremarked, but are experienced as pleasurable and empowering. That consciousness is not limited to cognition, but encompasses corporeal sensation (and sensitization) as a form of knowledge. While Queendom harks back to models of Marxist and feminist political theatre that are premised on the intermittent breaking of empathy, as the viewer mentally pulls back from the scene for the purpose of reflection, critical knowledge can also be generated from within the empathic process, as in Ehler's work, and even in Glow. In the moment when the manic exertions and sweaty face of the Afro-German dancer in Hamburg begin to grate against the trope of cosmopolitan creativity, spectators can begin to feel, and to know, the violent toll taken by creative industry on the body, even as work is now reframed as pleasurable self-actualization. Seeing him dance on the Reeperbahn, a famous red-light district, reminds us that, for many, pleasure has long been hard work, performed under precarious conditions and with uncertain rewards. Moreover, seeing the dancer isolated from the partying families makes palpable the recognition that not all bodies are able to convert pain into gain. An empathic response to the Hamburg dancer, then, can generate knowledge of racialized labour, exploitation and community that works against the logic of a European Wii/We as a whole. There, race becomes available as a fun, sexy and invigorating accessory that guides spectators towards an illusory mastery of their bodies as a precondition for artful synchronization with diverse others, as a metaphor for democratic self-determination. Desiring or identifying with the racialized logos of Europeanness invites us to 'sample' racist discourses without any awareness of the injuries these discourses have historically inflicted on racialized bodies, or without ethically responding to these histories. 
Glow's corporate cosmopolitanism relinquishes the link forged by Afro-European activists, scholars and artists between black visibility and a larger project of political (anti-racist and feminist) transformation, social critique and historical remembering. This message is not only relevant for the hundreds of thousands of Afro-Europeans, or the millions of Europeans with a 'migration background'. At a time of profound economic and political restructuring across the continent, the substitution of cosmopolitan diversity for economic and social equality, and the rehearsal of kinaesthetic communion rather than the practice of struggle, becomes a management technique affecting all Europeans.

NOTES

1 I thank Milija Gluhovic and Karen Fricker for organizing the Eurovision Song Contest and the New Europe group, which prompted this research, and Antje Wischmann for translating Queendom's videos into German. Jeremy Rifkin, The Empathic Civilization: The Race to Global Consciousness in a World in Crisis (New York: Penguin, 2009). Carolyn Calloway-Thomas, Empathy in the Global World: An Intercultural Perspective (London: SAGE, 2010).

4 Susan Leigh Foster, Choreographing Empathy: Kinesthesia in Performance (London and New York: Routledge, 2011).

5 Matthew Wilson Smith, The Total Work of Art: From Bayreuth to Cyberspace (New York, London: Routledge, 2007); Robin Curtis, 'Immersion und Einfühlung: Zwischen Repräsentationalität und Materialität bewegter Bilder', Montage A/V, 17, 2 (2008), pp. 89-107; Juliet Koss, Modernism after Wagner (Minneapolis: University of Minnesota Press, 2010).

6 Robert Vischer, 'On the Optical Sense of Form: A Contribution to Aesthetics', in Robert Vischer, Conrad Fiedler, Heinrich Wölfflin and Adolf Goller, Empathy, Form, and Space: Problems in German Aesthetics, 1873-1893 (Santa Monica: The Getty Center for the History of Art and the Humanities, 1994), pp. 89-124; Edith Stein, Zum Problem der Einfühlung (Munich: Kaffke, 1980; first published 1917). Stein, Zum Problem der Einfühlung, p. 17.

8 In her study of EU cultural policy, Monica Sassatelli shows that the EU Commission has predominantly funded international cultural collaborations in order to promote gradual familiarity and cohesion, rather than stipulating specific ideological visions of Europe as a prerequisite for funding. Monica Sassatelli, Becoming Europeans: Cultural Identity and Cultural Policies (Basingstoke: Palgrave Macmillan, 2009).

9 Katrin Sieg, 'Cosmopolitan Empire: Central and Eastern Europeans at the Eurovision Song Contest', European Journal of Cultural Studies 2012 (in press).

$10 \quad$ Kien Nghi Ha, Der Hype um Hybridität: Kultureller Differenzkonsum und postmoderne Verwertungstechniken im Spätkapitalismus (Berlin: Transcript, 2005).

11 See www.ssb.no/innvbef_en, accessed 20 April 2012.

12 A recent study of media and migration in the Nordic countries found only six films on the topic produced in Norway. Eva Bakoy, 'From Lonely Guest Workers to Conflict-ridden Diasporas: A Historical Survey of Norwegian Migrant Cinema', in Elisabeth Eide and Kaarina Nikunen, eds., Media in Motion: Cultural Complexity and Migration in the Nordic Region (London: Ashgate, 2011), pp. 145-62. Nadia Hasnaoui was born in Morocco to a Norwegian mother and Moroccan father; after her parents' divorce, she came to Norway with her mother. Eric Solbakken is a white Norwegian. Haddy Jatou N'Jie was born in Norway; her father had immigrated from the Gambia. 
Susan Manning, Ecstasy and the Demon: The Dances of Mary Wigman (Minneapolis: University of Minnesota Press, 2006). See www.youtube.com/watch?v=b3gEHRENCHc, accessed 9 July 2012. Image available at http://esc2010.webs.com/ShareTheMomentmodern.jpg Judith Hamera, 'The Precarious Excellence of Michael Jackson: Dancing American Deindustrialization', in Gabriele Brandstetter, Bettina Brandl-Risi and Kai van Eikels, eds., Prekäre Exzellenz: Künste, Oekonomien und Politiken des Virtuosen (Freiburg: Rombach Verlag, 2012), pp. 121-8. The lyrics for Glow can be found on several websites; this and all following quotations are taken from www.sweetslyrics.com/767504.Madcon\%20-\%20Glow.html, accessed 20 September 2012. Susanne Zantop traced the racialization of the family and the gendering of race in her reading of eighteenth- and nineteenth-century Germans' colonial fantasies, which emplotted the aspiration to explore and civilize the New World in a romance of submissive native princesses and benevolent conquerors. Susanne Zantop, Colonial Fantasies: Conquest, Family, and Nation in Precolonial Germany, 1770-1870 (Durham, NC and London: Duke University Press, 1995). I examine elsewhere how the relationship between east and west Europeans has been dramatized in similar terms at the Eurovision Song Contest (Sieg, 'Cosmopolitan Empire'). For historical background see Rainer E. Lotz, Black People: Entertainers of African Descent in Europe and Germany (Bonn: Birgit Lotz, 1997).

Historian Geoff Eley has demonstrated that the repression of past racist policies and eugenic practices, the taboo on the term 'race,' and the association of race with black Americans and African-American cultural products were broadly shared by continental European states in the post-war era. Geoff Eley, 'The Trouble with Race,' in Rita Chin, Heide Fehrenbach, Geoff Eley and Atina Grossmann, After the Nazi Racial State: Difference and Democracy in Germany (Ann Arbor: University of Michigan Press, 2009), pp. 137-81.

Derek Foster, “Wii're Here for a Good Time”: The Sneaky Rhetoric of Wii-Themed Parties', Journal of American Culture, 33, 1 (March 2010), pp. 30-9.

24 Foster, Choreographing Empathy, p. 7.

25 Nakamura has compared temporary appropriations of racialized identities online to tourism, and argues that it provides users with a 'false notion of cultural and racial understanding based on an episodic, highly mediated experience of travel'. Lisa Nakamura, 'Cyber-Race,' PMLA, 123, 5 (2008), pp. $1673-82$, here p. 1675 . 2005).

27 Aniko Imre discussed the branding campaigns of the EU and of CEE member states in her lecture 'Brand New EU: Nation Branding across Media', presented at Georgetown University, 11 April 2012.

Benedict Andersen, Imagined Communities: Reflections on the Origin and Spread of Nationalism (London: Verso, 1991).

29 For a critique of the EU as a model of neo-liberal governance by experts (rather than democratically elected politicians) see Perry Anderson, 'Depicting Europe', London Review of Books, 29, 18 (2007), pp. 1-30, here p. 14; and Cris Shore, Building Europe: The Cultural Politics of European Integration (London: Routledge, 2000). singers in Michael von der Heide's song 'Il pleut de l'or' for Switzerland, and Jessy Matador, the main singer/dancer for France, as well as several of his backup dancers, were black. See www.best.uni-mainz.de/modules/Informationen/index.php?id=13, www.utrop.no, www.Afrotak.wordpress.com, and http://afroeurope.blogspot.com, accessed 20 September 2012.

32 Chin et al., After the Nazi Racial State; Suvi Keskinen, Salla Tuori and Sari Arni, eds., Complying with Colonialism: Gender, Race, and Ethnicity in the Nordic Region (London: Ashgate, 2009); Darlene Clark Hine and Tricia Danielle Keaton, eds., Black Europe and the African Diaspora (Urbana: University of 
Illinois Press, 2009); Prem Poddar and Rajeev S. Patke, eds., A Historical Companion to Postcolonial Literature: Continental Europe and Its Empires (Edinburgh: Edinburgh University Press, 2009).

33 Mai Palmberg, 'The Nordic Colonial Mind', in Keskinen, Tuori and Arni, Complying with Colonialism, pp. 35-50, here p. 35. In Norway, which from 1523 to 1814 formed part of the Denmark-Norway Kingdom (and was subsequently under Swedish administration), the temptation to subscribe to a fiction of innocence was particularly strong, since some regard Norway as a former colony of Denmark.

34 Previews and excerpts of Ehler's work can be found on her website, www.jeannetteehlers.dk

35 Two episodes can be found online at www.nrk.no/nett-tv/klipp/559256, accessed 16 July 2012.

KATRIN SIEG (ks253@georgetown.edu) is Professor of German at Georgetown University. She is the author of three books on German and European theatre and performance, most recently Choreographing the Global in European Cinema and Theater (2008). She has published widely in the areas of feminist, queer and critical race studies as they intersect with performance in Germany. 